\title{
Sexual polymorphisms of vomeronasal 1 receptor family gene expression in bulls, steers, and estrous and early luteal-phase heifers
}

\author{
Haruna $\mathrm{KUBO}^{1)}$, Midori OTSUKA ${ }^{1)}$ and Hiroya KADOKAWA ${ }^{1) *}$ \\ 1) Joint Faculty of Veterinary Medicine, Yamaguchi University, 1677-1, Yamaguchi-shi, Yamaguchi 753-8515, Japan
}

(Received 18 May 2015/Accepted 29 September 2015/Published online in J-STAGE 18 October 2015)

\begin{abstract}
Vomeronasal 1 receptors (V1R) are a family of receptors for intraspecies chemosignals, including pheromones, and are expressed in the olfactory epithelium (OE) and vomeronasal organ (VO). Even in the well-studied rodents, it is unclear which members of the V1R family cause sexual polymorphisms, as there are numerous genes and it is difficult to quantify their expressions individually. Bovine species carry only $34 \mathrm{~V} 1 \mathrm{R}$ homologs, and the OE and VOs are large enough to sample. Here, V1R expression was quantified in the OE and VOs of individual bovines. Based on the 34 gene sequences, we obtained a molecular dendrogram consisting of four clusters and six independent branches. Semi-quantitative RT-PCR was used to obtain gene expression profiles in the VOs and OE of 5 Japanese Black bulls, 5 steers, 7 estrous heifers and 6 early luteal-phase heifers. Ten genes showed significant between-group differences, and 22 showed high expression in VOs than in OE. The bulls showed higher expression of one gene more in OE and another in VOs (both $P<0.05$ ) than did steers; both genes belonged to the first cluster. No genes were expressed more abundantly in steers than in bulls. The estrous heifers showed higher expression of a gene of the second cluster in OE, and a gene of the third cluster in VOs (both $P<0.05$ ) than did early luteal-phase heifers. These results suggest V1R expression exhibits sexual polymorphisms in cattle.

KEY WORDS: dendrogram, olfactory epithelium, pheromone, vomeronasal 1 receptor family, vomeronasal organ
\end{abstract}

doi: 10.1292/jvms.15-0300; J. Vet. Med. Sci. 78(2): 271-279, 2016

Intraspecies chemosignals, including pheromones, play an important role in social and reproductive behavior and physiology in mammals [42]. Vomeronasal 1 receptors (V1R) are a family of receptors for intraspecies chemosignals that have been well characterized in rodents. Rodents also express vomeronasal 2 receptors (V2R) genes, which are silenced in cows and humans [45]. V1R family homologs are expressed in neurons in the olfactory epithelium $(\mathrm{OE})$ and vomeronasal organ (VO) of goats $[29,32]$. Individual OE or VO neurons express only one or a few numbers of V1R or V2R $[15,19$, 28]. Sex differences in intraspecies chemosignal detection have been reported [5]. Therefore, better understanding of the expression of V1R will give improved insight into the evolution of intraspecies chemical communication and the perception of sex-specific intraspecies chemosignals.

Comparative genomic techniques have identified V1R family members in several species, although it is unclear which receptors are expressed in males and which in females. The V1R family is too large in mice, which carry 530 annotated V1R genes [21], and the size of the VO is insufficient to permit quantitative expression analysis in individual animals. RNA sequencing (RNAseq) was used to quantify full transcriptomes of the mouse $\mathrm{VO}$ and $\mathrm{OE}$, but pooled samples were required (VOs from three mice [21]; OE from eight mice [22]). In addition, RNAseq data for olfactory

*Correspondence to: Kadokawa, H., Joint Faculty of Veterinary Medicine, Yamaguchi University, 1677-1, Yamaguchi-shi, Yamaguchi 753-8515, Japan. e-mail: hiroya@yamaguchi-u.ac.jp

(C)2016 The Japanese Society of Veterinary Science

This is an open-access article distributed under the terms of the Creative Commons Attribution Non-Commercial No Derivatives (by-nc-nd) License $<$ http://creativecommons.org/licenses/by-nc-nd/3.0/>. receptor genes have yielded conflicting results. Ibarra-Soria et al. [21] reported that overall transcript levels are similar in $\mathrm{OE}$ between male and female mice, whereas Shiao et al. [41] suggested higher expression in males than in females.

Intraspecies chemosignals and receptors in bovines have not been extensively studied. However, pheromone-like volatile compounds are found in female feces [23, 39], skin and urine $[34,35]$, which induce Flehmen behavior and penile erection in male water buffalos. Urine and vaginal mucus obtained from estrous cows slightly suppress LH secretion in heifers [31]. Skins of estrous Japanese Black cows (Bos taurus) have greater levels of several volatile compounds in comparison to early luteal-phase cows [33]. Further details of cattle pheromones have recently been reviewed by Archunan et al. [4]. Therefore, bovines also may communicate using intraspecies chemosignals and V1Rs.

We recently performed in silico mining of the bovine genome database and discovered 34 V1R family homologs. We also obtained sufficient mRNA from the OE and VOs of individuals in a preliminary trial. Thus, the aim of the present study was to quantify and compare the expression of V1R genes in the OE and VOs of bulls, steers, and estrous and early luteal-phase heifers.

\section{MATERIALS AND METHODS}

Experiments were performed in accordance with the Guiding Principles for the Care and Use of Experimental Animals in the Field of Physiological Sciences (Physiological Society of Japan) and were approved by the Committee on Animal Experiments of the School of Veterinary Medicine, Yamaguchi University.

In silico mining of the bovine genome database: Nucleo- 
tide sequences were obtained from NCBI Bos taurus annotation release 103 . These genes were predicted by automated computational analysis, best-placed RefSeq Gnomon ver 5.1, against the bovine genome database (BioProject number was PRJNA33843) in DDBJ/GenBankTM/EBI Data Bank. Table 1 shows the gene names and NCBI reference sequences of the 34 V1R homologs.

Drawing a molecular dendrogram: The bovine V1R gene sequences were utilized to draw a molecular dendrogram using the two-parameter model and neighbor-joining method [24, 36] with Molecular Evolutionary Genetyx Analysis ver.6.0.5 (MEGA6 [44]). The evolutionary distances were computed using the maximum composite likelihood method [43]. Here, the 34 genes are numbered from the top of molecular dendrogram.

Collecting VOs and OE from bulls and steers: We collected VOs and OE from healthy, intact Japanese Black bulls $(\mathrm{n}=5,46 \pm 6$ months old, $838 \pm 11 \mathrm{~kg})$ and Japanese Black steers $(\mathrm{n}=5,28 \pm 1$ months old, $698 \pm 12 \mathrm{~kg})$ in a local slaughterhouse according to a previous anatomical study [38]. Water and mineral blocks were provided ad libitum. Italian ryegrass hay, rice straw and concentrate were provided according to the Japanese feeding standard [1]. Absence of disease, including reproductive disease, was confirmed by daily observation. The steers were castrated at 8 months old. It is generally difficult to obtain sufficient number of bull samples in any country. The bulls were used for "Sumo" wrestling in western Japan and were very healthy-they were being sacrificed after losing wrestling rank, not for health reasons. Presence or absence of testis was confirmed in each bull or steer at the slaughterhouse. The heads were placed on ice within $5 \mathrm{~min}$ of slaughter. VOs and OE were obtained within $15 \mathrm{~min}$ of slaughter using a disk grinder with a diamond blade, hammer, straight gouge and scissors. The tissues surrounding the VOs and OE were carefully removed and washed with phosphate-buffered saline (PBS). The VOs and $\mathrm{OE}$ were frozen in liquid nitrogen and preserved at $-80^{\circ} \mathrm{C}$ until use for RNA extraction.

Collecting VOs and OE from heifers: We collected VOs and OE from Japanese Black heifers in estrus $(n=7,30 \pm 1$ months old, $506 \pm 10 \mathrm{~kg})$ or early luteal phase $(\mathrm{n}=6,30 \pm 1$ months old, $505 \pm 10 \mathrm{~kg}$ ). Water and mineral blocks were provided ad libitum. Italian ryegrass hay and concentrate were provided according to the Japanese feeding standard [1]. Absence of disease, including reproductive disease, was confirmed by daily observation. All heifers had received two intramuscular injections of $20 \mathrm{mg}$ dinoprost (Pronalgon $\mathrm{F}$, Pfizer, Tokyo, Japan) given 11 days apart to synchronize the estrous cycle. Estrous behavior and ovulation were monitored at the farm; ovarian and uterine morphology were confirmed at the slaughterhouse. The VOs and OE were collected from the heifers and stored as described above.

RNA extraction, cDNA synthesis and semi-quantitative $P C R$ : Total RNA was extracted from frozen $\mathrm{VO}$ and $\mathrm{OE}$ samples with RNAiso Plus (Takara Bio Inc., Otsu, Japan) according to manufacturer's protocols. The RNA solution was extracted a second time with RNAiso Plus, because single extraction yielded a brown product that inhibited RT-PCR that could only be removed by a second extraction (preliminary study, data not shown). We could not use a column method for RNA extraction due to the mucus and brown powder in the VO and OE samples. Total RNA samples were digested with DNase I (Promega, Madison, WI, U.S.A.) to remove contaminating genomic DNA. RNA concentration and purity were evaluated by using a NanoDrop ND-1000 spectrophotometer (NanoDrop Technologies, Wilmington, DE, U.S.A.) to ensure the A260/A280 nm ratio was in the acceptable range of 1.8-2.1. Electrophoresis of total RNA followed by staining with ethidium bromide was performed to verify mRNA quality; the $28 \mathrm{~S}: 18 \mathrm{~S}$ ratios were $2: 1$. We synthesized cDNA from $2 \mu \mathrm{g}$ RNA in $20-\mu l$ reactions with random hexamer primers and the precise High-capacity cDNA reverse transcription kit (Applied Biosystems, Foster City, CA, U.S.A.). PCR conditions were optimized by conventional PCR with Tks Gflex DNA Polymerase (Takara Bio), 20 ng DNase-treated reversetranscribed RNA, a Veriti Thermal Cycler (Applied Biosystems) and primers. Experiments included a no-template control and a no reverse transcription control. In preliminary experiments, the optimum cycle number was determined for each target, so that signals were always in the exponential portion of the amplification curve. Typical cycling conditions were as follows: $94^{\circ} \mathrm{C}$ for $1 \mathrm{~min}$, followed by 35 cycles of $98^{\circ} \mathrm{C}$ for $10 \mathrm{sec}, 60^{\circ} \mathrm{C}$ for $15 \mathrm{sec}$ and $68^{\circ} \mathrm{C}$ for $30 \mathrm{sec}$.

Primers were designed with Primer Express Software v3.0 (Applied Biosystems) and reference sequences. All primers were produced by a commercial service (Fasmac Co., Ltd., Atsugi, Japan). Table 1 shows the $34 \mathrm{~V} 1 \mathrm{R}$ homologs and primers. Amplicons for most targets were $300 \mathrm{bp}$ with the following exceptions: Gene 2 (280 bp), Gene 3 (220 bp), Gene 6 (210 bp), Gene 10 (210 bp), Gene 13 (217 bp), Gene 14 (320 bp), Gene 15 (383 bp), Gene 16 (200 bp), Gene 23 (338 bp), Gene 24 (220 bp) and Gene 26 (250 bp). The presence of a single product was confirmed by $2 \%(\mathrm{w} / \mathrm{v})$ agarose gel electrophoresis (Sigma-Aldrich, Saint Louis, MO, U.S.A.). Molecular weight markers ranging from 0.1 to $20 \mathrm{kbp}$ (Gene Ladder Wide 1; Nippon Gene, Tokyo, Japan) were used to identify the bands. PCR products were visualized with a highly sensitive fluorescent stain (Gelstar, Lonza, Allendale, NJ, U.S.A.) and a charge-coupled device (CCD) imaging system (GelDoc; Bio-Rad, Hercules, CA, U.S.A.), and the sensitivity of this system against double-strand DNA was $20 \mathrm{pg}$.

PCR product concentrations were calculated by comparing the band strength of the unknown samples to the molecular weight markers using Alphaview software (Proteinsimple, Santa Clara, CA, U.S.A.). V1R gene expression was normalized to the geometric means of two housekeeping genes, chromosome 2 open reading frame 29 (C2orf29; XM_002691150.2) and suppressor of zeste 12 (SUZ12; NM_001205587.1); values for each gene were divided by the geometric mean of C2orf29 and SUZ12 in each sample. The primers for C2orf29 and SUZ12 were reported elsewhere [30].

All PCR-amplified products were purified with the NucleoSpin Gel and PCR Clean-up Kit (Takara Bio) and ExoSAP-IT (Affymetrix, Santa Clara, CA, U.S.A.), and then sequenced the Dye Terminator v3.1 Cycle Sequencing Kit on 
Table 1. Gene numbers in this study (numbered from the top of the molecular dendrogram), gene name from cow sequence, accession number and details of PCR primers

\begin{tabular}{|c|c|c|c|c|c|}
\hline \# & Gene name & Accession number & Primer & Nucleotide & Sequence (5'to $\left.3^{\prime}\right)$ \\
\hline \multirow[t]{2}{*}{1} & V1R407 & XM_002695263.3 & up & $27-49$ & TGGAGAACGTTGGGTTTTAGTTA \\
\hline & & & down & $306-326$ & TGAAATCCACCGGAGAACAGA \\
\hline \multirow[t]{2}{*}{2} & $V N 1 R 4 l$ & XM_002695264.3 & up & $425-445$ & CACTGAGACCTGACGGCATGT \\
\hline & (LOC100337475) & & down & $684-704$ & CGAACGTACGGGAAAAATCTG \\
\hline \multirow[t]{2}{*}{3} & VNt1R4l & XM_005195507.1 & up & $16-34$ & CTGGCCATGTTGCCTTGTG \\
\hline & (LOC100847477) & & down & $213-235$ & TAGAGGATCCTGAATGGGAACAC \\
\hline \multirow[t]{2}{*}{4} & $V 1 R 413$ & XM_002695269.2 & up & $391-413$ & AGTGTCTTCCAGGTCATCACCAT \\
\hline & & & down & $671-690$ & AGAGCCACTGGCCAAGATTG \\
\hline \multirow[t]{2}{*}{5} & $V 1 R 410$ & XM_002695266.2 & up & $13-38$ & TATGAAGTATTGGTACGTGGAGAATG \\
\hline & & & down & $288-312$ & CAGAACCAAGATGTTACCTACGATC \\
\hline \multirow[t]{2}{*}{6} & $V 1 R 406$ & XM_002695262.2 & up & $33-52$ & CAGGTGTCCGGCTGAAGAGA \\
\hline & & & down & $218-242$ & AGTAGCAGGTCAACAAAAATCCAAT \\
\hline \multirow[t]{2}{*}{7} & VNt1R4l & XM_005195506.1 & up & $411-430$ & ACTCCAGGTGGGCAGAGCTT \\
\hline & (LOC101908711) & & down & $689-710$ & GGACTCTCTGCTTGCACCTGTA \\
\hline \multirow[t]{2}{*}{8} & $\operatorname{V1R} 411$ & XM_001789862.3 & up & $549-571$ & GTTGATGTCCTTCCCTGATGTGT \\
\hline & & & down & $829-848$ & GGGCTGATAGTTGGGAAGCA \\
\hline \multirow[t]{2}{*}{9} & $V 1 R 416$ & XM_002695271.1 & up & $3-23$ & GGCCAGCATTGATTTGACAAT \\
\hline & & & down & $283-302$ & AGGCAGATGCTACCGATGGA \\
\hline \multirow[t]{2}{*}{10} & $\operatorname{V1R} 414$ & XM_001254649.3 & up & $26-44$ & CCAGGCTCGTGGATTTGTG \\
\hline & & & down & $214-235$ & GGTGTGTGCTGTATGCATCATG \\
\hline \multirow[t]{2}{*}{11} & $\operatorname{V1R} 415$ & XM_001254634.2 & up & $90-113$ & TATCGTCCTTCACATCATGGGTTA \\
\hline & & & down & $368-389$ & GGAACGGTGTACTTGGGAGCTA \\
\hline \multirow[t]{2}{*}{12} & VN1R2 & XM_002695278.2 & up & $42-62$ & GGAAGCCCGAGTGAAGAACAG \\
\hline & & & down & $321-341$ & GAAAGGAGGGCCAAGATGTTG \\
\hline 13 & $\operatorname{V1R} 418$ & XM_001789884.1 & up & $774-793$ & GAGTCCAGAGCCACCCAAAG \\
\hline & & & down & $965-990$ & GTACAGAAAGCAGAGACTGGATATGA \\
\hline 14 & $V 1 R 420$ & XM_001254581.1 & up & $68-89$ & ACCTTGAATGACACCACAGCTC \\
\hline & & & down & $369-386$ & AAGAGGCAGGTTGTGCCA \\
\hline 15 & $\operatorname{V1R} 421$ & XM_001789887.1 & up & $3-29$ & GTCACAAATTTATATGAGCCATTCTAT \\
\hline & & & down & $269-386$ & ACTCAAGAGGCAGGTGGTACTG \\
\hline 16 & $V 1 R 417$ & XM_001789881.3 & up & $27-46$ & ССтTTTTCCTGCGTCCAGAA \\
\hline & & & down & $205-226$ & AGCCAACTTTCCTTGTGTGCTT \\
\hline 17 & $V 1 R 419$ & XM_001254591.2 & up & $257-277$ & TCTCAAAAGGGCTCCCTCAGA \\
\hline & & & down & $537-556$ & TGCGCCATTTGTCAGAAACA \\
\hline 18 & $V N 1 R 1$ & XM_005219819.1 & up & $446-464$ & GCGCCCTCTAGGCACTGAT \\
\hline & & & down & $726-745$ & CCCGTGGCTACTCTGTGGAA \\
\hline 19 & VNt1R4l & XM_005215403.1 & up & $24-44$ & GCGTTTTGCACACCAGTTACC \\
\hline & (LOC100847223) & & down & $304-323$ & TGTCCCCTTGGAGACGAGAA \\
\hline 20 & $\operatorname{V1R} 427$ & XM_002695464.1 & up & $191-213$ & TGATTATTTTCTCCCCTGGGATT \\
\hline & & & down & $469-490$ & TACCCTGTGGACCAGTGACTGT \\
\hline 21 & $V N 1 R 4 l$ & XM_002695460.3 & up & $355-373$ & ACCCCCAGGAGAGCGAAGT \\
\hline & (LOC100295682) & & down & $637-654$ & CACCCTCTGGCGGTGTCT \\
\hline 22 & $V 1 R 433$ & XM_002695465.1 & up & $182-202$ & TGATGGCAGCTTTTGTGTCAA \\
\hline & & & down & $459-481$ & ACTTGCCTTGGGCATCAGTATAG \\
\hline 23 & $V 1 R 426$ & XM_002695403.2 & up & $1-18$ & ATGTCTCTAAGGGGCCAC \\
\hline & & & down & $318-338$ & GTGCTGAGAGCCATCCTCTGT \\
\hline 24 & VNt1R1l & XM_003585332.1 & up & $37-56$ & TGCATCAACTCCCTGCAGAA \\
\hline & (LOC100851211) & & down & $245-256$ & AATGTGGCAGAACCATCTGTGT \\
\hline 25 & $V 1 R 425$ & XM_001788382.2 & up & $88-111$ & GTCAATGTCATCCTTTTCTTCCAA \\
\hline & & & down & $366-387$ & TCTGAGCAATGACCTCCCTTCT \\
\hline 26 & $V 1 R 432$ & XM_002695457.2 & up & $359-380$ & CTGGGAGAGAAGGGAGGTCACT \\
\hline & & & down & $589-608$ & GACCAGACCATGAGGCCAAT \\
\hline 27 & VN1R1l & XM_002695462.2 & up & $564-582$ & GTGGTCCACCTCGGATGCT \\
\hline & (LOC100295623) & & down & $844-863$ & AAGGGAGAAACGGTGGGAAA \\
\hline 28 & $V 1 R 428$ & XM_002695463.2 & up & $316-336$ & TTTCACAAAGACGCCCTGAGA \\
\hline & & & down & $598-615$ & GGTGCTGCGAGCCATTTT \\
\hline 29 & $\operatorname{V1R} 431$ & XM_002695458.3 & up & $329-348$ & ATGGCTGTGGCCAATCTCTT \\
\hline & & & down & $606-628$ & TTTGAGAGGAACACGGATGTACA \\
\hline 30 & $V 1 R 424$ & XM_002695400.2 & up & $253-276$ & TCCAGTCTTGGGTGTAAGTTTGTG \\
\hline & & & down & $534-552$ & GCCTGTGGCAGCACCTGTA \\
\hline 31 & VIR430 & XM_002695461.3 & up & $17-38$ & ATGCCCTGAGAACCATAATCCA \\
\hline & & & down & $273-296$ & GCCACCCTCTGTACATAAAACACA \\
\hline 32 & $V 1 R 437$ & XM_601821.1 & up & $64-83$ & ATTGGGATCTTGGCCAACAC \\
\hline & & & down & $345-363$ & TGCCAGACGGGAGTTTCTG \\
\hline 33 & $V 1 R 403$ & XM_002695191.2 & up & $309-329$ & GAGTGCCTACCAAGCCATCAC \\
\hline & & & down & $589-608$ & AGACTGGACCACGCCATGAG \\
\hline 34 & $V 1 R 404$ & XM_002695192.2 & up & $349-369$ & AAGTGGGCGTGGCTTAGATCT \\
\hline & & & down & $629-648$ & CTGGACTCTCTGGCGGTGTT \\
\hline
\end{tabular}


an ABI3130 (Applied Biosystems). The obtained sequences were used as query terms for homology searches in the DDBJ/ GenBankTM/EBI Data Bank using the basic nucleotide local alignment search tool (BLAST) optimized for highly similar sequences (available on the NCBI website).

Statistical analysis: Data were analyzed using Statview version 5.0 for Windows (SAS Institute, Inc., Cary, NC, U.S.A.). Two-factor analysis of variance (ANOVA) was used to evaluate the effect of organ (VO or OE), group (bulls, steers, estrous heifers or early luteal-phase heifers) and interaction between the effects of organ and group on V1R gene expression followed by post-hoc comparisons with Fisher's protected least significant difference (PLSD) test. The statistical significance of differences among groups was assessed by one-factor ANOVAs followed by post-hoc comparisons with Fisher's PLSD test using a model consisting of variance from the effect of group and the residual. The level of significance was set at $P<0.05$. Data are expressed as mean \pm SEM.

\section{RESULTS}

Molecular dendrogram of bovine homologous genes of $V 1 R$ : Figure 1 shows the molecular dendrogram of 34 bovine V1R homologs. The molecular dendrogram has 31 nodes and 34 leaves. There were four clusters: Gene 1 to Gene 8; Gene 9 to Gene 11; Gene 13 to Gene 17; and Gene 20 to Gene 31. There was six independent branches for Genes 12, $18,19,32,33$ and 34 .

General information of gene expression of bovine V1R homologs: Housekeeping genes C2orf29 and SUZ12 were amplified from all cDNA samples. No amplified products were obtained from the no-template controls and no reverse transcription controls. Therefore, we concluded the cDNAs were suitable for further analysis.

No amplified products were obtained from primers specific for Genes 3, 6, 16 and 23. It was impossible to design better primers for these genes, which were thus excluded from further analysis.

Figures 2, 3 and 4 show V1R mRNA expression in the $\mathrm{OE}$ and VO of bulls, steers, estrous heifers and early lutealphase heifers, and outcomes of ANOVA. The organ effect (OE or VO) was significant for 22 genes (Genes 2, 4, 5, 7, 8, $9,10,12,13,14,15,17,18,20,21,25,26,28,30,31,33$ and $34)$, all of which were more highly expressed in VOs than in the OE. The effect of group (bulls, steers, estrous heifers or early luteal-phase heifers) was significant for ten genes (Genes 2, 12, 15, 17, 18, 22, 24, 26, 28 and 34). The interaction between the effects of organ and group was significant for five genes (Genes 2, 12, 15, 17 and 20).

Bulls vs. steers: Gene 1 expression in the OE was higher in the bull than in the steer. Gene 7 expression in VOs was higher in the bull than in the steer. Furthermore, no genes showed higher expression in steers than in bulls.

Estrous heifers vs. early luteal-phase heifers: Gene 9 showed higher expression in the OE of estrous heifers than in the OE of early luteal-phase heifers. Gene 15 showed higher expression in the VOs of estrous heifers than in the
VOs of early luteal-phase heifers. Eight genes (Genes 5, 12, $17,20,22,28,33$ and 34) showed higher expression in VOs of early luteal-phase heifers than in those of estrous heifers. Furthermore, no genes showed higher expression in the OE of early luteal-phase heifers than in the OE of estrous heifers.

Bulls vs. estrous or early luteal-phase heifers: The expression of gene 1 in the OEs was higher in bulls than in both estrous and early luteal-phase heifers. The expressions of three genes $(12,17$ and 33) were higher in the VOs of bulls than of estrous heifers, but not of early luteal-phase heifers. The expression of gene 15 in the VOs was higher in bulls than in early luteal-phase heifers, but not in estrous heifers. The expression of gene 26 in the VOs was higher in estrous heifer than in bulls, but not in early luteal-phase heifers. Further, the expressions of six genes $(2,12,18,20,22$ and 28) were higher in the VOs of early luteal-phase heifers than of bulls.

\section{DISCUSSION}

This study clarified sexual polymorphisms of V1R gene expression in bovine VOs and OE. Although intraspecies chemosignals and receptors in this species are poorly understood, the expression polymorphisms discovered herein suggest the presence of multiple intraspecies chemosignals in females and males. The genomes of mice, bovines and humans contain 530, 34 and 4 V1R family genes [16, 21]; thus, bovines represent a mid-point in the loss of V1R genes through evolution. Therefore, the results of this study may give an insight into the evolution of such receptor genes in mammals and their involvement in sex-specific behavior.

It is well known that there are sex differences in intraspecies chemosignal detection [5], although the mechanisms for these sex differences were unknown in mammals prior to this study. Indeed, sexual polymorphisms in V1R gene expression remain unknown in all mammalian species. Our study results show higher gene expression in bulls than in estrous heifers (genes 1, 12, 17 and 33). In addition, we also show higher gene expression in estrous heifers than in bulls (gene 26). Therefore, we believe that these genes may be important causes of sex differences in intraspecies chemosignal detection. Our results also suggest that different receptor clusters may have different roles and effects on the central nervous system. However, we believe that other mechanisms for sex differences in intraspecies chemosignal detection may exist in cattle. Indeed, a recent study, which was published after we completed our study, showed that progesterone can silence sensory neurons detecting urinary protein pheromones in female mice [12].

The estrous heifers showed higher expression of Gene 9 in $\mathrm{OE}$ and Gene 15 in VOs in comparison to early luteal-phase heifers. The VOs of early luteal-phase heifers showed higher expression of eight genes than those of estrous heifers. These data suggest expression is dependent on estrous cycle stage. Blood estradiol is higher in estrous heifers than in early luteal-phase heifers [8]. This and the findings of Doty and Cameron [14] suggest estradiol may be one controlling factor. Interestingly, mouse VO synthesizes estrogen, and the $\mathrm{VO}$ neuronal response to putative urine pheromones is 


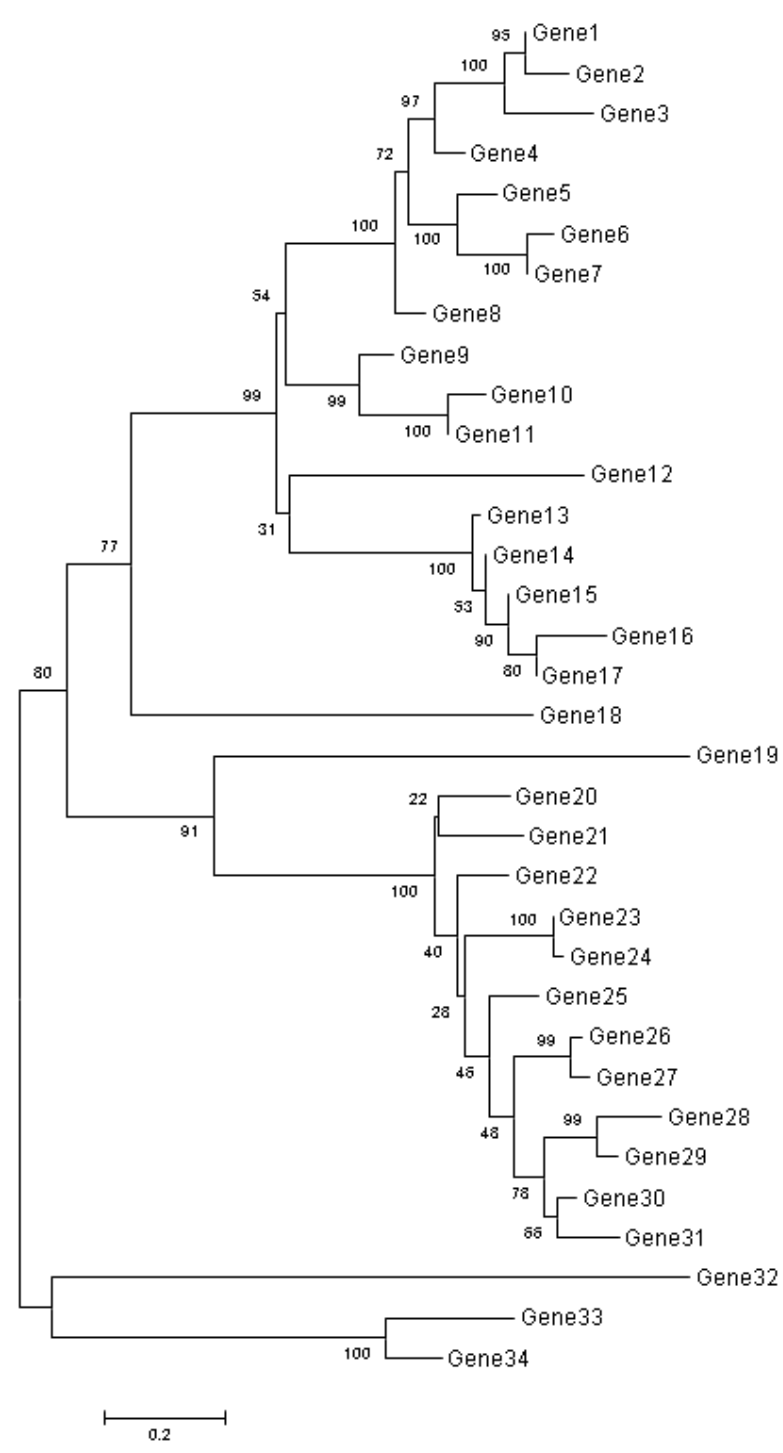

Fig. 1. The evolutionary history of the 34 bovine homologs of V1R was inferred using the Neighbor-Joining method. The percentage of replicate trees in which the associated taxa clustered together in the bootstrap test is shown next to the branches. The tree is drawn to scale, with branch lengths in the same units as those of the evolutionary distances used to infer the phylogenetic tree. The evolutionary distances were computed using the Maximum composite likelihood method, and units represent the number of base substitutions per site.

reduced by estradiol [9]. Two V2R genes may be controlled by testosterone in male mice [2]. We found no previous reports on the effect of sex steroids on V1R gene expression; however, the ability to detect putative human pheromone, androstenone, is more likely to diminish in boys than in girls after puberty $[10,13,27]$. Further studies are required to test the hypothesis that estradiol and testosterone control sexassociated polymorphisms in V1R gene expression.

The VOs expressed 22 genes more strongly than the OE. Little is known about V1R expression in ruminants. Ohara et al. [32] reported that all of the 24 identified V1R genes are expressed in the VO and $\mathrm{OE}$ of a goat, the genome of which has not been fully sequenced. However, the authors did not report on the characteristics of the goat (age, sex and intact or gonadectomized), and they used nested PCR (both first and second PCRs were 35 cycles) to evaluate gene expression. Therefore, it is impossible to compare our data with theirs. Sniffing is the behavioral response for pheromone binding to the OE receptors, and Flehmen is the behavioral response for pheromone binding to the VO receptors. In general, bulls and cows show Flehmen responses after sniffing [20]. Therefore, the smaller number of ligand-receptor binding sites on the $\mathrm{OE}$ may be enough to induce the Flehmen response, and a higher number of ligand-receptor binding sites on the VOs may be interpreted (or treated) by the accessory olfactory bulb and lead to various neurological and behavioral effects in cattle [38].

The effect of group was not significant for the $20 \mathrm{~V} 1 \mathrm{R}$ genes. Sexual pheromones induce male and female effects to activate reproductive functions in the opposite sex in small ruminants [11, 17, 37]. However, an intraspecies chemosignal was reported in Dorsett ewes, which utilize their VO for neonatal offspring recognition [7]. Rats have the ability to communicate affective states, such as stress, alarm, fear, anxiety or sexual interest, by releasing intraspecies chemosignals $[25,26]$. Therefore, some of the $20 \mathrm{~V} 1 \mathrm{Rs}$ may have important roles in the detection of intraspecies chemosignals for non-sexual purposes.

We compared the expression of each of $30 \mathrm{~V} 1 \mathrm{Rs}$ in the $\mathrm{VO}$ and OE among the 4 different groups. Individual gene expression patterns did not show uniformity. Because all $30 \mathrm{~V} 1 \mathrm{Rs}$ are orphan receptors, it is impossible to explain the precise characteristics of each receptor and explain the relationship with each physiological change or gene expression requirement. However, generally, physiological responses and decisions of animals are in response to situations in their living environment and for survival and species conservation. Intraspecies chemosignals have sexual and non-sexual purposes $[3,6,18]$. Rodents can discriminate among conspecific animals based on various sensory cues, including dietary history [6], illness-associated state [3] and major histocompatibility complex [18]. Therefore, expression patterns of V1Rs may have important roles in complex intraspecific chemical communication.

Tks Gflex DNA Polymerase possesses high fidelity and excellent extension activity, because it contains a specific priming accelerator that suppresses non-specific binding, Takara Bio's original strong elongation factor and reaction buffer elements that sequester PCR inhibitors. Thus, the polymerase can amplify templates from over a wide range of nucleic acid concentrations, even from targets containing GC- or AT-rich sequences. In our preliminary trials, PCR amplification failed, likely because of inhibiting contaminants, and we subsequently evaluated several cDNA reverse transcription kits and enzymes and concluded that the highcapacity cDNA reverse transcription kit and Tks Gflex provided the best PCR results.

Ibarra-Soria et al. [21] used RNAseq to quantify whole transcriptomes of the mouse $\mathrm{VO}$ and $\mathrm{OE}$; however, they 

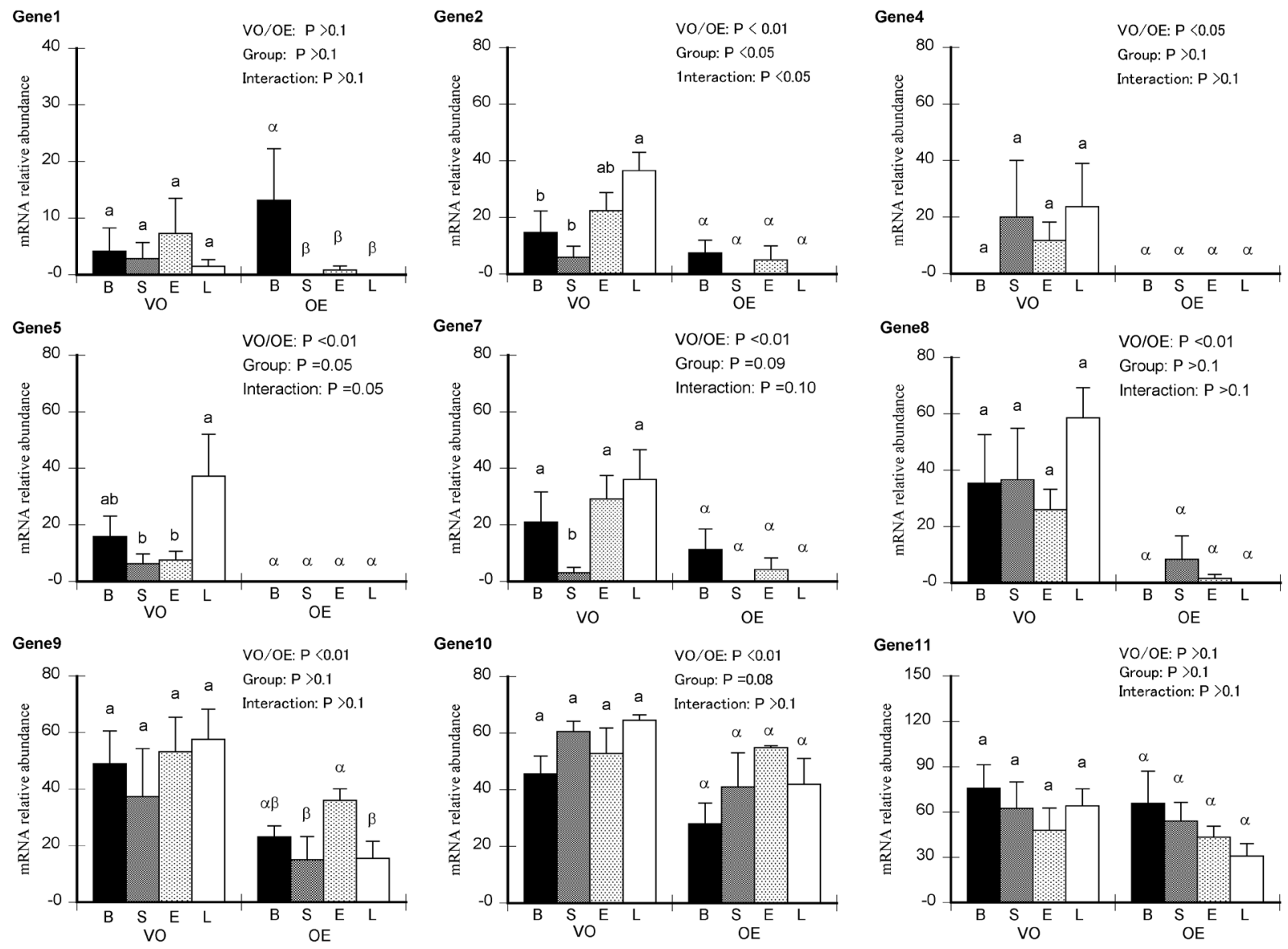

Fig. 2. The expression of bovine V1R homologs Genes 1 to 11 in the VO and OE of bulls (B; black bar), steers (S; dark gray bars), estrous heifers (E; dotted bars) and early luteal-phase heifers (L; white bars). V1R gene expressions were normalized to the geometric means of two housekeeping genes, C2orf 29 and SUZ12; values for each gene were divided by the geometric mean of C2orf29 and SUZ12 in each sample. The header in the upper right corner of each graph represents the results of two-factor ANOVA followed by Fisher's PLSD test, including the effect of organ (VO or OE), effect of group (bulls, steers, estrous heifers or anestrous heifers) and interaction between the effects of organ and group. Letters (a, b or $\mathrm{c}$ ) above the left-side bars indicate significant between-group differences in expression in VOs; Greek letters $(\alpha$ or $\beta)$ above the right-side bars indicate significant between-group differences in expression in OEs (One-factor ANOVA followed by Fisher's PLSD test).

measured only one VIR gene among the 530 annotated V1R genes by using real-time PCR with a commercial primer and probe set. The amplicon size was $59 \mathrm{bp}$ for the commercial primer and probe set; however, the sequences of primers and probe in the set were not specified. Thus, it was impossible to compare the homology of the 59-bp amplified products with that of the other 529 genes. In this study, we did not include any real-time PCR analysis data, because first, we did not obtain a product by using Tks Gflex, which could be because of the high risk of failure to amplify due to the presence of inhibiting contaminants. Second, it is difficult to ensure specificity, because of the high level of sequence similarity within the V1R family [21]. Third, for precise real-time PCR analysis results, the amplicon size must be less than $150 \mathrm{bp}$ (and more than $50 \mathrm{bp}$ ) [40]. However, such small amplicon size is insufficient to obtain sequence data for BLAST search to identify the gene. Fourth, the manufacturer of the Dye Terminator Cycle Sequencing Kit, namely, Applied Biosystems, advised us that the excitation and emis- sion wavelengths of the fluorescent dyes used in real-time PCR kits are almost similar to those of the fluorescent dyes used in the Dye Terminator Cycle Sequencing Kit. Therefore, the manufacturer was unable to guarantee the quality of the sequence data of the amplified products obtained by realtime PCR. Therefore, we used semi-quantitative RT-PCR followed by sequencing for identification of the expressed gene in the present study; however, we must be cautious, because quantification by using semi-quantitative RT-PCRs may not always be accurate.

Typically, mRNA expression does not accurately reflect protein expression. In addition, the number of receptors on the cell surface is not solely controlled by their mRNA expressions. Therefore, specific antibodies to extra-cellular regions of each receptor must be developed to clarify the role and importance of each V1R.

In conclusion, in this study, we discovered sexual polymorphisms of V1R expressions among bulls, steers, and estrous and early luteal-phase heifers. This is the first report 

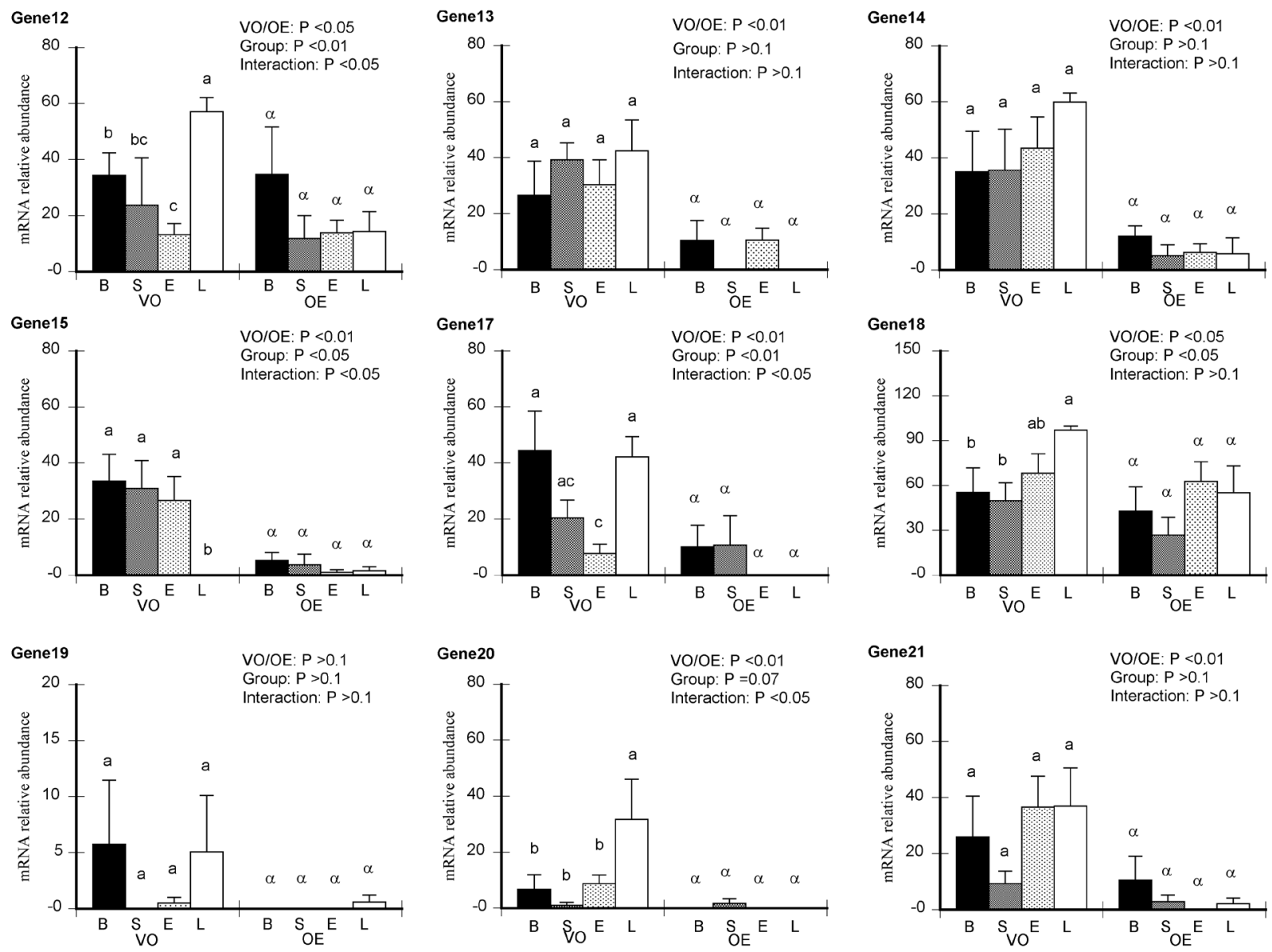

Fig. 3. The expression of bovine V1R homologs Genes 12 to 21 in the VO and OE of bulls (B; black bar), steers (S; dark gray bars), estrous heifers (E; dotted bars) and early luteal-phase heifers (L; white bars). V1R gene expressions were normalized to the geometric means of two housekeeping genes, C2orf 29 and SUZ12; values for each gene were divided by the geometric mean of C2orf 29 and SUZ12 in each sample. The header in the upper right corner of each graph represents the results of two-factor ANOVA followed by Fisher's PLSD test, including the effect of organ (VO or OE), effect of group (bulls, steers, estrous heifers or anestrous heifers) and interaction between the effects of organ and group. Letters ( $\mathrm{a}, \mathrm{b}$ or $\mathrm{c}$ ) above the left-side bars indicate significant between-group differences in expression in VOs; Greek letters $(\alpha$ or $\beta)$ above the right-side bars indicate significant between-group differences in expression in OEs (One-factor ANOVA followed by Fisher's PLSD test).

of sexual polymorphisms of V1R expression in ruminant species and the first reported estrous stage-dependent difference of V1R expression in any mammalian species.

ACKNOWLEDGMENTS. This research was partly supported by a Grant-in Aid for Scientific Research from Yamaguchi University Foundation (Yamaguchi, Japan) to H. Kadokawa. The authors thank people of Shimane prefectural government, Shimane meat public corporation and JA Shimane in Japan for supplying the bovine samples used in this study. The authors declare no conflict of interest that could be perceived as prejudicing the impartiality of the research reported.

\section{REFERENCES}

1. Agriculture, Forestry and Fisheries Research Council Secretariat. 2008. Nutrition requirement. pp 31-48. In: Japanese Feeding Standard for Beef Cattle. (Ministry of Agriculture, Forestry and
Fisheries. ed.) Central Association of Livestock Industry, Tokyo.

2. Alekseyenko, O. V., Baum, M. J. and Cherry, J. A. 2006. Sex and gonadal steroid modulation of pheromone receptor gene expression in the mouse vomeronasal organ. Neuroscience 140: 1349-1357. [Medline] [CrossRef]

3. Arakawa, H., Cruz, S. and Deak, T. 2011. From models to mechanisms: odorant communication as a key determinant of social behavior in rodents during illness-associated states. Neurosci. Biobehav. Rev. 35: 1916-1928. [Medline] [CrossRef]

4. Archunan, G., Rajanarayanan, S. and Karthikeyan, K. 2014. Cattle pheromone. pp. 461-488. In: Neurobiology of Chemical Communication. (Mucignat-Caretta, C. eds.) CRC Press, Boca Raton.

5. Baum, M. J. and Bakker, J. 2013. Roles of sex and gonadal steroids in mammalian pheromonal communication. Front. Neuroendocrinol. 34: 268-284. [Medline] [CrossRef]

6. Beauchamp, G. K. 1976. Diet influences attractiveness of urine in guinea pigs. Nature 263: 587-588. [Medline] [CrossRef]

7. Booth, K. K. and Katz, L. S. 2000. Role of the vomeronasal organ in neonatal offspring recognition in sheep. Biol. Reprod. 63: 

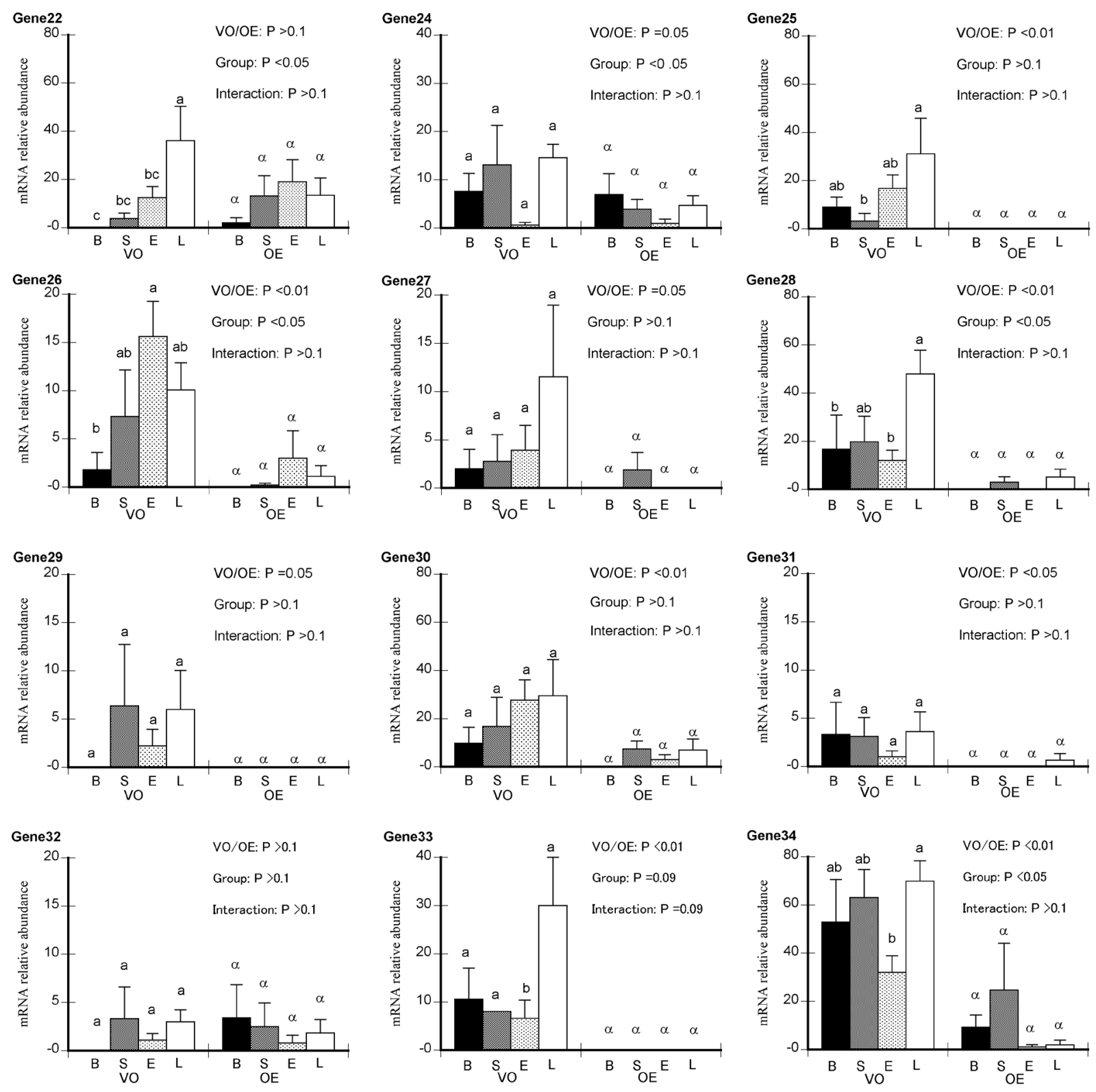

Fig. 4. The expression of bovine V1R homologs Genes 22 to 34 in the VO and OE of bulls (B; black bar), steers (S; dark gray bars), estrous heifers (E; dotted bars) and early luteal-phase heifers (L; white bars). V1R gene expressions were normalized to the geometric means of two housekeeping genes, C2orf 29 and SUZ12; values for each gene were divided by the geometric mean of C2orf 29 and SUZ12 in each sample. The header in the upper right corner of each graph represents the results of two-factor ANOVA followed by Fisher's PLSD test, including the effect of organ (VO or OE), effect of group (bulls, steers, estrous heifers or anestrous heifers) and interaction between the effects of organ and group. Letters ( $\mathrm{a}, \mathrm{b}$ or $\mathrm{c}$ ) above the left-side bars indicate significant between-group differences in expression in VOs; Greek letters $(\alpha$ or $\beta)$ above the right-side bars indicate significant between-group differences in expression in OEs (One-factor ANOVA followed by Fisher's PLSD test).

953-958. [Medline] [CrossRef]

8. Bryner, R. W., Garcia-Winder, M., Lewis, P. E., Inskeep, E. K. and Butcher, R. L. 1990. Changes in hormonal profiles during the estrous cycle in old lactating beef cows. Domest. Anim. Endocrinol. 7: 181-189. [Medline] [CrossRef]

9. Cherian, S., Wai Lam, Y., McDaniels, I., Struziak, M. and Delay, R. J. 2014. Estradiol rapidly modulates odor responses in mouse vomeronasal sensory neurons. Neuroscience 269: 43-58. [Medline] [CrossRef]
10. Chopra, A., Baur, A. and Hummel, T. 2008. Thresholds and chemosensory event-related potentials to malodors before, during, and after puberty: differences related to sex and age. Neuroimage 40: 1257-1263. [Medline] [CrossRef]

11. De Bond, J. A., Li, Q., Millar, R. P., Clarke, I. J. and Smith, J. T. 2013. Kisspeptin signaling is required for the luteinizing hormone response in anestrous ewes following the introduction of males. PLoS ONE 8: e57972. [Medline] [CrossRef]

12. Dey, S., Chamero, P., Pru, J. K., Chien, M. S., Ibarra-Soria, X., 
Spencer, K. R., Logan, D. W., Matsunami, H., Peluso, J. J. and Stowers, L. 2015. Cyclic regulation of sensory perception by a female hormone alters behavior. Cell 161: 1334-1344. [Medline] [CrossRef]

13. Dorries, K. M., Schmidt, H. J., Beauchamp, G. K. and Wysocki, C. J. 1989. Changes in sensitivity to the odor of androstenone during adolescence. Dev. Psychobiol. 22: 423-435. [Medline] [CrossRef]

14. Doty, R. L. and Cameron, E. L. 2009. Sex differences and reproductive hormone influences on human odor perception. Physiol. Behav. 97: 213-228. [Medline] [CrossRef]

15. Dulac, C. and Axel, R. 1995. A novel family of genes encoding putative pheromone receptors in mammals. Cell 83: 195-206. [Medline] [CrossRef]

16. Grus, W. E., Shi, P., Zhang, Y. P. and Zhang, J. 2005. Dramatic variation of the vomeronasal pheromone receptor gene repertoire among five orders of placental and marsupial mammals. Proc. Natl. Acad. Sci. U.S.A. 102: 5767-5772. [Medline] [CrossRef]

17. Hawken, P. A. and Martin, G. B. 2012. Sociosexual stimuli and gonadotropin-releasing hormone/luteinizing hormone secretion in sheep and goats. Domest. Anim. Endocrinol. 43: 85-94. [Medline] [CrossRef]

18. Hegde, A. N. 2003. MHC molecules in the vomeronasal organ: contributors to pheromonal discrimination? Trends Neurosci. 26: 646-650. [Medline] [CrossRef]

19. Herrada, G. and Dulac, C. 1997. A novel family of putative pheromone receptors in mammals with a topographically organized and sexually dimorphic distribution. Cell 90: 763-773. [Medline] [CrossRef]

20. Houpt, K. A., Rivera, W. and Glickstein, L. 1989. The flehmen response of bulls and cows. Theriogenology 32: 343-350. [Medline] [CrossRef]

21. Ibarra-Soria, X., Levitin, M. O., Saraiva, L. R. and Logan, D. W. 2014. The olfactory transcriptomes of mice. PLoS Genet. 10: e1004593. [Medline] [CrossRef]

22. Kanageswaran, N., Demond, M., Nagel, M., Schreiner, B. S., Baumgart, S., Scholz, P., Altmüller, J., Becker, C., Doerner, J. F., Conrad, H., Oberland, S., Wetzel, C. H., Neuhaus, E. M., Hatt, H. and Gisselmann, G. 2015. Deep sequencing of the murine olfactory receptor neuron transcriptome. PLOS ONE 10: e0113170. [Medline] [CrossRef]

23. Karthikeyan, K., Muniasamy, S., SankarGanesh, D., Achiraman, S., Ramesh Saravanakumar, V. and Archunan, G. 2013. Faecal chemical cues in water buffalo that facilitate estrus detection. Anim. Reprod. Sci. 138: 163-167. [Medline] [CrossRef]

24. Kimura, M. 1980. A simple method for estimating evolutionary rates of base substitutions through comparative studies of nucleotide sequences. J. Mol. Evol. 16: 111-120. [Medline] [CrossRef]

25. Kiyokawa, Y., Kikusui, T., Takeuchi, Y. and Mori, Y. 2004. Alarm pheromones with different functions are released from different regions of the body surface of male rats. Chem. Senses 29: 35-40. [Medline] [CrossRef]

26. Kiyokawa, Y., Shimozuru, M., Kikusui, T., Takeuchi, Y. and Mori, Y. 2006. Alarm pheromone increases defensive and risk assessment behaviors in male rats. Physiol. Behav. 87: 383-387. [Medline] [CrossRef]

27. Lundström, J. N., Hummel, T. and Olsson, M. J. 2003. Individual differences in sensitivity to the odor of 4,16-androstadien-3-one. Chem. Senses 28: 643-650. [Medline] [CrossRef]

28. Matsunami, H. and Buck, L. B. 1997. A multigene family encoding a diverse array of putative pheromone receptors in mammals. Cell 90: 775-784. [Medline] [CrossRef]

29. Murata, K., Wakabayashi, Y., Kitago, M., Ohara, H., Watanabe, H., Tamogami, S., Warita, Y., Yamagishi, K., Ichikawa, M.,
Takeuchi, Y., Okamura, H. and Mori, Y. 2009. Modulation of gonadotrophin-releasing hormone pulse generator activity by the pheromone in small ruminants. J. Neuroendocrinol. 21: 346-350. [Medline] [CrossRef]

30. Nahar, A. and Kadokawa, H. 2014. Suppressed expression of macrophage migration inhibitory factor in the oviducts of lean and obese cows. Reprod. Fertil. Dev. (in press). [Medline] [CrossRef]

31. Nordéus, K., Båge, R., Gustafsson, H., Humblot, P. and Söderquist, L. 2012. The influence of oestrous substances on cyclicity and oestrous behaviour in dairy heifers. Acta Vet. Scand. 54: 26. [Medline] [CrossRef]

32. Ohara, H., Nikaido, M., Date-Ito, A., Mogi, K., Okamura, H., Okada, N., Takeuchi, Y., Mori, Y. and Hagino-Yamagishi, K. 2009. Conserved repertoire of orthologous vomeronasal type 1 receptor genes in ruminant species. BMC Evol. Biol. 9: 233. [Medline] [CrossRef]

33. Otsuka, M., Murakami, A., Kubo, H. and Kadokawa, H. 2014. Volatile compounds in skins of estrous cows, anestrous cows, steers, and bulls. p. 571. In: Reproduction in Domestic Ruminants VIII (Juengel J. L., Miyamoto, A., Price, C., Reynolds, L. P., Smith, M. F. and Webb, R. eds.). Nottingham University Press, Nottingham.

34. Rajanarayanan, S. and Archunan, G. 2004. Occurrence of flehmen in male buffaloes (Bubalus bubalis) with special reference to estrus. Theriogenology 61: 861-866. [Medline] [CrossRef]

35. Rajanarayanan, S. and Archunan, G. 2011. Identification of urinary sex pheromones in female buffaloes and their influence on bull reproductive behaviour. Res. Vet. Sci. 91: 301-305. [Medline] [CrossRef]

36. Saitou, N. and Nei, M. 1987. The neighbor-joining method: a new method for reconstructing phylogenetic trees. Mol. Biol. Evol. 4: 406-425. [Medline]

37. Sakamoto, K., Wakabayashi, Y., Yamamura, T., Tanaka, T., Takeuchi, Y., Mori, Y. and Okamura, H. 2013. A population of kisspeptin/neurokinin B neurons in the arcuate nucleus may be the central target of the male effect phenomenon in goats. PLoS ONE 8: e81017. [Medline] [CrossRef]

38. Salazar, I., Sánchez-Quinteiro, P., Alemañ, N. and Prieto, D. 2008. Anatomical, immnunohistochemical and physiological characteristics of the vomeronasal vessels in cows and their possible role in vomeronasal reception. J. Anat. 212: 686-696. [Medline] [CrossRef]

39. Sankar, R. and Archunan, G. 2008. Identification of putative pheromones in bovine (Bos taurus) faeces in relation to estrus detection. Anim. Reprod. Sci. 103: 149-153. [Medline] [CrossRef]

40. Schmittgen, T. D. 2006. Quantitative gene expression by realtime PCR: a complete protocol. pp. 127-137. In: Real-time PCR (Dorak, M. T. ed.). Taylor and Francis Group, New York.

41. Shiao, M. S., Chang, A. Y., Liao, B. Y., Ching, Y. H., Lu, M. Y., Chen, S. M. and Li, W. H. 2012. Transcriptomes of mouse olfactory epithelium reveal sexual differences in odorant detection. Genome Biol. Evol. 4: 703-712. [Medline] [CrossRef]

42. Stowers, L. and Kuo, T. H. 2015. Mammalian pheromones: emerging properties and mechanisms of detection. Curr. Opin. Neurobiol. 34: 103-109. [Medline] [CrossRef]

43. Tamura, K., Nei, M. and Kumar, S. 2004. Prospects for inferring very large phylogenies by using the neighbor-joining method. Proc. Natl. Acad. Sci. U.S.A. 101: 11030-11035. [Medline] [CrossRef]

44. Tamura, K., Stecher, G., Peterson, D., Filipski, A. and Kumar, S. 2013. MEGA6: Molecular Evolutionary Genetics Analysis version 6.0. Mol. Biol. Evol. 30: 2725-2729. [Medline] [CrossRef]

45. Young, J. M. and Trask, B. J. 2007. V2R gene families degenerated in primates, dog and cow, but expanded in opossum. Trends Genet. 23: 212-215. [Medline] [CrossRef] 